\title{
Desencuentros entre el imaginario social occidental y el imaginario social indígena: elementos para una reflexión teórica sobre los imaginarios sociales nucleares en el marco del conflicto entre el estado-nación chileno y el pueblo mapuche ${ }^{1}$
}

\begin{abstract}
Disagreements between western social imaginary and indigenous social imaginary: elements for a theoretical reflection on nuclear social imaginaries in the context of the conflict between the nation-state and the Mapuche people of Chile
\end{abstract}

\author{
Eduardo Gallegos Krause \\ Universidad de La Frontera, Chile
}

\begin{abstract}
RESUMEN El presente trabajo de orientación eminentemente teórica tiene por objetivo realizar un diagnóstico mediante un método sintético con énfasis hipotético-deductivo que dé cuenta de cuáles son los imaginarios nucleares del Estado nación chileno, por una parte, y del Pueblo mapuche por la otra, todo esto en el marco del conflicto entre Estado-nación y Pueblo mapuche. La aproximación teórica vincula los imaginarios sociales con la construcción de la identidad y la alteridad, para esto se utilizarán los aportes en torno a los imaginarios sociales desarrollados fundamentalmente por Castoriadis y actualizados por Manuel Antonio Baeza, sin desmedro de otros aportes. El análisis particular de los elementos constituyentes de los imaginarios en estudio per-
\end{abstract}

1. El presente trabajo se enmarca dentro del proyecto PIA-ANID/ANILLOS SOC180045, titulado: Horizontes Convergentes: Producción, mediatización, recepción y efectos de las representaciones culturales de la marginalidad. Agradezco a los/las revisores/as anónimos de este trabajo por sus pertinentes comentarios. 
mite identificar y caracterizar un imaginario nuclear occidental (del Estadonación) basado en la idea de modernidad-desarrollo y un imaginario nuclear indígena (del Pueblo mapuche) basado en el principio de renovación con una concepción cíclica y no lineal del tiempo.

PALABRAS CLAVES Imaginarios sociales; modernidad; desarrollo; Pueblo mapuche.

ABSTRACT This theoretical work aims to make a diagnosis, by means of a synthetic method with an hypothetical-deductive emphasis, about which are the nuclear social imaginaries of the Chilean nation-state and the Mapuche people, in the context of the conflict between nation-state and Mapuche people. The theoretical approach links the social imaginaries with the construction of identity and otherness. The Castoriadis's contributions around the social imaginary and the theoretical updates by Manuel Antonio Baeza, are used, without detracting from other contributions. The analysis allows to identify and characterize a Western nuclear imaginary based on the idea of modernity-development and an indigenous nuclear imaginary based on the principle of renewal with a cyclical rather than linear time conception.

KEY WORDS Social imaginaries; modernity; development; Mapuche people.

\section{Marco contextual y metodología: conflicto de imaginarios entre estado-nación/ pueblo mapuche y una perspectiva deductivo-sintética para su análisis}

El Estado-nación chileno comienza a surgir luego de la independencia decimonónica y particularmente en su relación con el Pueblo mapuche no carece de elementos socio-históricos previos que se relacionan sucesivamente con la conquista española del territorio (s. XVI-XVII), la articulación de una zona fronteriza de relaciones socio-económicas entre mapuches y españoles (s. XVIII-XIX) y finalmente la ocupación militar del Wallmapu ${ }^{2}$ para la anexión de territorio en la configuración del moderno Estado-nación de Chile en la segunda mitad del 1800 (Bengoa, 2002; Pinto, 2003; 2008; Saavedra, 2002). En este sentido, se sigue aquí, como se verá, lo señalado

2. Al abocarse el presente trabajo al análisis de los imaginarios y las construcciones significativosimbólicas que operan tras la representación del espacio y de las relaciones entre identidad-alteridad, se prefiere utilizar el concepto Wallmapu para designar el territorio. Del mismo modo, el concepto de Pueblo Mapuche y nación mapuche usado a lo largo de estas páginas remite al reconocimiento de una comunidad otra y diferenciada. Ver al respecto, por ejemplo, Millalén (2012); VV.AA (2012); Quidel (2016); Quiroga \& Villegas (2016); entre otros. 
por Nahuelpán (2007) respecto a que los dos principales sucesos históricos en torno a la configuración de la identidad latinoamericana son, primero, el (des)encuentro entre españoles e indígenas y, segundo, la crisis de independencia y la formación del estado-nación en Chile. Según el autor citado, es con el segundo hito donde se imponen las nociones de progreso, civilización y modernización, que como se verá, tienen implicancias concretas y actuales en la conformación de los imaginarios sociales en conflicto.

Por cuanto la creación de la nación es una artificialidad, podemos hablar de una "comunidad política imaginada como inherentemente limitada y soberana" (Anderson, 1993, p. 23) que es imaginada porque sus miembros no se conocerán todos unos a otros, es comunidad porque a pesar de lo anterior sienten un compañerismo profundo -más allá de la desigualdad y explotación a la que se sometan unos a otros- es limitada porque fija fronteras finitas y es soberana porque tiene pretensiones de libertad (Anderson, 1993, pp. 23-25). Anderson, describe una serie de raíces culturales que hicieron posible la formación de las naciones europeas, cuestión que por ahora no es aquí relevante, la referencia a este trabajo se justifica en cuanto central respecto a la reflexión de la nación como una comunidad construida o imaginada. Esta cuestión que es hoy reconocida hace emerger otras posibilidades de nación que en su tiempo fueron silenciadas e invisibilizadas, como en el caso de la "nación mapuche":

"Y muchas "naciones antiguas", que se creían plenamente consolidadas, se ven desafiadas por "sub" nacionalismos dentro de sus fronteras, es decir, nacionalismos que naturalmente sueñan con desprenderse de ese sufijo "sub", un buen día" (Anderson, 1993, p. 19).

De esta forma, lo que se observa hoy en el marco del conflicto Estado-nación y Pueblo mapuche, es una visibilización de las demandas autonómicas del movimiento mapuche, que articulan elementos como cultura, territorio, identidad, etc. (Beccaria, 2008; Tricot, 2009). En este sentido, Salazar (2002) señala la convergencia entre distintos movimientos indigenistas en América Latina hacia la demanda por la Autonomía que el autor asocia a la revitalización étnica. Esta cuestión llevará inevitablemente -sobretodo en la segunda mitad de este trabajo- a cuestionar las nociones coloniales aprendidas en torno a la definición de lo propio o de lo que se ha construido como "la idea de América Latina" (Mignolo, 2007). Del mismo modo, y también siguiendo a Mignolo en torno a la superación de lo colonial, se remitirá a variados pensadores mapuche que apuestan por la transformación epistémica.

En el marco de la teoría de los imaginarios sociales, particularmente aquella desarrollada por Cornelius Castoriadis y actualizada por los trabajos de Manuel Antonio Baeza, se propone una lectura de los imaginarios nucleares que constituyen la base identitaria de los dos grupos en conflicto (Estado-nación y Pueblo mapuche). Se pretende entonces analizar el desencuentro desde los imaginarios sociales considerando 
que el conflicto entre ambos grupos se debe al desencuentro o lo disímil de los imaginarios sociales que definen las demandas y expectativas de cada uno, de modo que este artículo tiene como objetivo principal analizar los imaginarios sociales nucleares que se encuentran en ambos lados del conflicto. La naturaleza teórica del presente ensayo implica que sea el marco teórico conceptual el que al mismo tiempo se constituye en una herramienta metodológica -o teórico-metodológica si se quiere- donde se aprovecha una conceptualización previa para dar cuenta de un fenómeno social de manera coherente y en línea con esa conceptualización. En este sentido, el razonamiento deductivo permite aquí unir la teoría con la observación al mismo tiempo que otorga un marco para la observación de los fenómenos que se identifican (Dávila, 2006). El primer paso consiste entonces en la presentación del conocimiento general asociado a los imaginarios sociales que permitirá luego acercarse a la particularidad de los imaginarios sociales asociados a la occidentalidad (Estado-nación) y a la indigenidad (Pueblo mapuche) donde se plantean lecturas posibles en forma de hipótesis con base en intuición y fuentes secundarias (Álvarez-Gayou, 2003). En este sentido, y a decir de Cornelius Castoriadis - quizás la figura consular en torno a los imaginarios sociales-, estas lecturas, interpretaciones o análisis de los imaginarios sociales son siempre una discusión y un diagnóstico de carácter político:

Surge entonces la pregunta: ¿cómo proceder para comprender estas significaciones imaginarias sociales? Aquí no hay metodología ni "respuesta" definible. $\mathrm{Y}$ ante todo, ¿cómo comprendemos nosotros las significaciones imaginarias sociales de nuestra propia sociedad? (...) También sería una discusión política, por cierto, pero es sobre todo una discusión sobre el diagnóstico, sobre la comprensión de lo que es" (Castoriadis, 2004, p. 32).

Este diagnóstico no es unívoco, es una toma de posición y de ahí que tal como lo define Castoriadis, se vuelve una discusión política. Alguien puede decir (diagnosticar), por ejemplo, que la significación social imaginaria nuclear de nuestra sociedad es una modernidad-colonialidad que avasalla la alteridad, y otro podría decir que es un bienestar general de libertad y desarrollo... "Hay pues un asunto de comprensión de estas significaciones imaginarias sociales, que, de hecho, se vuelve una recreación poética [y política]" (Castoriadis, 2004, p. 32).

También en relación a cuestiones referidas al método, y a la consideración de las particularidades de los imaginarios del pueblo mapuche y del Estado-nación chileno, la visión hipotético-deductiva antes señalada se mezcla con la inducción al observar ya no la generalidad de los imaginarios sociales sino la particularidad de las visiones de mundo asociados a la indigenidad y la occidentalidad. En este sentido es que se visualiza una perspectiva sintética que comienza con un énfasis en lo hipotéticodeductivo y que a partir de ahí avanza a las particularidades (inducción) de los imaginarios en estudio. 
Las deducciones hechas a partir de la teoría y al visualizar los constituyentes particulares de los imaginarios indígenas y occidentales, permitirán proponer una serie de hipótesis expresadas en forma de preguntas que podrían ser interesantes para consecutivos análisis e investigaciones.

\section{Imaginarios sociales, identidad y alteridad}

Los imaginarios sociales se entienden como constructos simbólicos que son parte de la capacidad instituyente y constructiva de los grupos humanos en cuanto seres sociales que se sustentan fundamentalmente en el lenguaje como elemento de experiencia compartida en la producción de significados que, según Mayorga, del Valle y Brown (2013) se constituyen en base a dispositivos de poder, sin embargo, recojo de su definición el carácter de "constructos de sentido", "construidos socialmente":

"[Los imaginarios sociales] Corresponden a constructos de sentido acerca de "algo o alguien", singular o plural, individual o colectivo, público o privado, que han sido construidos socialmente a través de los dispositivos de poder existentes dentro del tejido social y que poseen un reconocimiento y legitimidad dentro del conjunto de la sociedad" (Mayorga et al., 2013, p. 504).

Por cuanto el lenguaje y las significaciones imaginarias básicas que dan lugar a la capacidad constructiva e instituyente son ya creadas, es que se habla de la doble cualidad de los imaginarios en cuanto elementos estructurantes y estructurados, siendo imposible reconocer la socio-génesis de lo imaginario, y por tanto, de lo social.

Toda la realidad está entonces entretejida con lo simbólico y las relaciones de sentido o prácticas significantes, y es esto lo que se nos presenta en el mundo históricosocial en tanto construcción o imaginación de sentido y de realidad.

“Toda gran obra filosófica es una creación imaginaria, ella es creación de estas significaciones particulares que son las significaciones filosóficas. Éstas no son productos racionales (...) Estas son grandes invenciones, a partir de las cuales se aclara un conjunto de hechos concernientes al ser, al mundo a la naturaleza, al pensamiento humano y su relación con el otro, etcétera. (...) Existe un parentesco profundo entre el arte, por un lado, y la filosofía y la ciencia, por el otro. No solamente vemos a la imaginación creadora en acción en estos campos, sino que tanto el arte como la filosofía y la ciencia tratan de brindar una forma al caos: al caos subyacente al cosmos, el mundo que se encuentra detrás de los sucesivos estratos de las apariencias" (Castoriadis, 2005, p. 102). 
Los imaginarios sociales, significaciones socialmente construidas, dan entonces sentido al caos, otorgan un marco de acción y de actitudes esperadas y vedadas. Las significaciones sociales imaginarias en la relación Estado-nación y Pueblo mapuche, responden sin dudas a estas lógicas de invención e institucionalización, en algunos casos con pretensiones de institucionalización (imaginarios sociales instituyentes) o ya de facto institucionalizadas (imaginarios sociales instituidos). Institucionalización que está anclada fuertemente en lo simbólico que se constituye en orden de lo social. Se trata entonces de adosar significados (formas representacionales) a diversos significantes y símbolos, los cuales en su conjunto dan lugar a un orden social indispensable que encontramos en todas las sociedades humanas (Baeza, 2008, p. 63).

Más allá de querer teorizar o realizar una revisión exhaustiva respecto de la compleja cuestión de lo simbólico, se pretende aquí, dejar en claro la relación entre lo simbólico-significativo con lo imaginario. Con respecto a la complejidad de lo simbólico, Baczko señala que es posible encontrar "demasiado" o "demasiado poco" en las definiciones, hipótesis y análisis que se realizan al respecto en las ciencias humanísticas y que esto presenta problemas para psicólogos y sociólogos, semióticos y antropólogos.

"Al verse obligado a "chapucear" con lo que tiene a su disposición [respecto a lo simbólico-significacional] acaso lo que más retiene es, en especial, que los símbolos designan tanto al objeto como las reacciones del sujeto hacia ese objeto; que la función del símbolo no es sólo la de instituir distinciones, sino también la de introducir valores y de modelar conductas individuales y colectivas; que todo símbolo está inscripto en una constelación de relaciones con otros símbolos; que las formas simbólicas que van desde lo religioso a lo mágico, desde lo económico a los político, etcétera, forman un campo en donde se articulan las imágenes, las ideas y las acciones" (Baczko, 2005, p. 29).

En relación a lo simbólico y la identidad, la construcción de un imaginario social sobre la identidad es un mecanismo simbólico-significativo de toda colectividad humana. En este sentido, se cumplen las definiciones y relaciones otorgadas a lo simbólico en razón de distinción, articulación de ideas y acciones, valorizaciones colectivas. No es de extrañarse entonces que en la relación mapuche/no-mapuche aparezcan ineludiblemente significaciones imaginarias relativas a la identidad del uno y del otro, o sea a la distinción entre "nosotros" y los "otros", o "identidad" y "alteridad".

"Toda sociedad hasta ahora ha intentado dar respuesta a cuestiones fundamentales: ¿quiénes somos como colectividad?, ¿qué somos los unos para los otros?, ¿qué queremos, qué deseamos, qué nos hace falta? La sociedad debe definir su "identidad", su articulación, el mundo, sus relaciones con él y con los objetos que contiene, sus necesidades y sus deseos" (Castoriadis, 2007, p. 236). 
La identidad (el nosotros) se construye entonces en oposición a otro, a un "alter" (los otros), donde este otro es en sí mismo una construcción de sentido, una institución tan imaginaria como la propia identidad. Así, no podemos separar, sino con un fin explicativo y taxonómico, la cuestión de la identidad-alteridad. En efecto, siempre que se habla de lo que "soy", se define también de manera implícita lo que "no soy", de manera que el "yo" no puede existir sin el "otro", donde la dinámica Alter/Ego se expresa precisamente como tal, como un movimiento que va de un lado a otro y que define de manera simultánea la identidad y la alteridad. Respecto de la cuestión sobre esta definición de los "otros" en términos de imaginarios sociales Baczko (2005) señala:

"Designar su identidad colectiva es, por consiguiente, marcar su "territorio" y las fronteras de éste, definir sus relaciones con los "otros", formar imágenes de amigos y enemigos, de rivales y aliados; del mismo modo, significa conservar y modelar los recuerdos pasados, así como proyectar hacia el futuro sus temores y esperanzas" (Baczko, 2005, p. 28).

Queda claro entonces que los imaginarios estructuran nociones de sentido común, usuales y cotidianas como la propia identidad y la construcción consecuente de alteridades u otredades. Se considera así pertinente la definición de Riffo (2016) en torno a los imaginarios sociales:

“(...) son estructuras compartidas socialmente, las cuales se encuentran, sin excepción en cada uno de los seres humanos. Estas estructuras imaginarias están construidas logomíticamente a través de mitos, relatos, arquetipos, símbolos, estudios, etc. y viven dentro de nuestro universo simbólico" (Riffo, 2016, p. 67).

\section{Imaginarios sociales nucleares y lo socio-histórico}

Los imaginarios sociales están relacionados con la capacidad de los individuos de evocar imágenes simbólicas en tanto que sujetos autónomos, y a través de las que se le otorga sentido al mundo de manera intersubjetiva. Sin embargo esta "capacidad imaginativa" de los sujetos particulares constituye un orden simbólico diferente de lo social, pues es lo social lo que adquiere supremacía sobre el imaginario radical entendido como capacidad imaginativa particular.

La institución de la sociedad se relaciona con la facultad creadora ya referida y que se enmarca en el campo histórico-social, se trata de colectividades humanas anónimas, que hacen ser instituciones que les permiten existir como colectividades. No sólo la creación pertenece al ser socio-histórico, sino también la diferenciación de sociedades y la alteración histórica permanente, lenta o repentina. En este sentido, no es posible entender las diferenciaciones simbólicas que constituyen mutua y recí- 
procamente la identidad y la alteridad en el marco del conflicto actual entre Estadonación y Pueblo mapuche si antes no se intenta entender el sustrato imaginario que sostiene las formas de contacto que han llevado a cabo durante 500 años mapuches y no-mapuches.

"La sociedad constituye cada vez su orden simbólico, en un sentido totalmente otro del que el individuo puede hacer. Pero esta institución no es «libre». Debe también tomar su materia en «lo que ya se encuentra ahí» (...) Todo simbolismo se edifica sobre las ruinas de los edificios simbólicos precedentes, y utiliza sus materiales (...)" (Castoriadis, 2007, p. 194).

En cuanto elementos estructurantes existen imaginarios sociales que son nucleares de determinadas culturas y épocas socio-históricas, de manera que su identificación se vuelve un diagnóstico relevante a la hora de estudiar las formas en que se imagina determinada sociedad. Así mismo, existen imaginarios periféricos que se constituyen en torno a los nucleares, aunque es preciso señalar que estas relaciones no son estáticas y que un imaginario que hoy es considerado nuclear, puede luego ser desechado en el marco de la (re)construcción social permanente a la que están sujetas las instituciones humanas (Baczko, 2005; Baeza, 2003, 2008; Castoriadis, 2004, 2005, 2007, entre otros).

Así, resulta imperativo para comprender el desarrollo de esta facultad histórica de dos colectividades que se interpelan abordar los imaginarios sociales nucleares, tanto los relativos al Estado-nación como los asociados al Pueblo mapuche, considerando que ambos se encuentran como base de las significaciones sociales en el marco del conflicto.

Tal como se señaló en la descripción metodológica para realizar el análisis de estos imaginarios nucleares y periféricos se propone una interpretación sintética que va desde lo general de los imaginarios sociales a visualizar las particularidades de los imaginarios occidentales e indígenas, de manera de generar un diagnóstico o una interpretación de estos conjuntos significantes que son los imaginarios, la idea de diagnóstico es precisamente la afirmada por Castoriadis: "Aquí no hay metodología ni "respuesta" definible. (...) es sobre todo una discusión sobre el diagnóstico, sobre la comprensión de lo que es" (Castoriadis, 2004, p. 32).

No queda sino realizar entonces una toma de partido; un diagnóstico sobre lo que se considera la significación social imaginaria nuclear que define las instituciones imaginarias que están a la vez en el centro y en los márgenes del conflicto estadonación/pueblo mapuche. Así, se escrutará a continuación y por separado lo que aquí se propone como diagnóstico del imaginario nuclear del Estado-nación (u occidental) y del imaginario nuclear del Pueblo mapuche (o indígena). 
Se trata de la búsqueda de las significaciones centrales de lo mapuche y lo no mapuche para vislumbrar un núcleo imaginario organizativo del discurso para cada actor, a fin de comprender las relaciones sociales o en palabras de Baeza, "aprehender las relaciones esenciales entre esencias (...) el estudio relacional entre dos o más imaginarios sociales (por simple contacto o por derivación sincrética)" (Baeza, 2008, p. 483).

"Lo que decimos se refiere a lo que puede llamarse lo imaginario central de cada cultura, ya se sitúe en el nivel de los símbolos elementales o en el de un sentido global. Evidentemente hay, además, lo que puede llamarse lo periférico, no menos importante en sus efectos reales (...) Corresponde a una segunda o enésima elaboración imaginaria de los símbolos, a unas capas sucesivas de sedimentación" (Castoriadis, 2007, p. 210).

\section{El imaginario nuclear occidental: modernidad y desarrollo}

Se opta, como diagnóstico y postura política dicho está, considerar el imaginario occidental de la modernidad/desarrollo como el constituyente nuclear de las significaciones vehiculadas por el Estado-nación chileno en el marco del conflicto con el Pueblo mapuche que hasta el día de hoy impregnan la discusión no sólo sobre lo mapuche/no-mapuche, sino otro tipo de disensiones vinculadas al riesgo ambiental, lo político, el desarrollo de la ciencia, los movimientos sociales, etc.

Describir este imaginario central de la modernidad/desarrollo ${ }^{3}$ que articula nuestro mundo simbólico y las significaciones sociales imaginarias inherentes resulta entonces clave para dar cuenta de la realidad social.

Como primera definición la modernidad estaría igualada a la concepción de desarrollo (Wallerstein, 2007, p. 96); una suerte de evolucionismo social que obliga a pasar de lo pre-moderno a lo moderno, y que justifica el difusionismo y colonialismo. La concepción lineal-esquemática de la historia, el descubrimiento/invención ${ }^{4} \mathrm{de}$ América es uno de los constituyentes de la modernidad y delimita el nacimiento del sistema-mundo moderno capitalista o el comienzo de una occidentalización global (Wallerstein, 2007). Luego, con la ilustración europea se avanza en un nuevo estadio de desarrollo de la modernidad: el proyecto moderno ilustrado se funda en la primacía de la razón como vehículo del desarrollo humano para salir de la "minoría de

3. Como se verá, esta idea de modernidad-desarrollo retoma las ideas de pensadores, a esta altura clásicos, que han denunciado el eurocentrismo y las distintas dinámicas que de esto afloran. Sin ánimo de exhaustividad menciono, por ejemplo, los conceptos de: colonialidad/modernidad (Mignolo, 2007); colonialidad del poder (Quijano, 2000); moderno sistema mundo (Wallerstein, 2006); hybris del punto cero (modernidad/colonialidad) (Castro-Gómez, 2005).

4. De aquí en adelante se usará el interesante concepto de "encubrimiento" de América desarrollado por O'Gorman (1995). 
edad" (Kant, 2004). La modernidad funda así una serie de dualidades opuestas (dicotomías) como oposiciones fundantes y perdurables de una nueva forma de sociedad (ritualismo/racionalismo; mito/historia; emoción/razón; civilización/barbarie; etc.) (Dube, 2009). Son estas significaciones sociales imaginarias, esta institución imaginaria, la que se constituye en el núcleo imaginario que hasta el día de hoy nutre las formas simbólicas de distinción entre Estado-nación y Pueblo mapuche; ente lo mapuche y lo no-mapuche.

"Es también que como un legado duradero de la idea desarrollista de historia universal, natural, y como una representación engrandecedora de una modernidad exclusiva, occidental, tales antinomias han encontrado una variedad de expresiones entre los distintos temas que han nombrado, descrito y objetivado desde, al menos, el siglo xviii." (Dube, 2009, p. 175).

A partir de lo hasta aquí señalado y aplicando el modelo esquemático para dar cuenta de la articulación de los imaginarios sociales desarrollado por Baeza (2003, 2008), el imaginario de la modernidad-desarrollo se articularía en un contexto de occidentalización pretendida donde se presentaría como enigmático la respuesta en torno al concepto clave de desarrollo. En este escenario de incertidumbre (enigma) surgirían dos posibles respuestas: una positiva $[+]$ donde el desarrollo se actualiza en la modernidad, y una negativa [-] donde el desarrollo no se concreta y se establece una situación de pre-modernidad.

Así, la modernidad/desarrollo surge como un proyecto ilustrado difusionista que se gesta desde Europa, y que desde comienzos del s.XX incluye a Estados Unidos, por lo que se habla de un universalismo pan-europeo (Wallerstein, 2007) para referirnos a esta significación social imaginaria. Wallerstein desarrolla la idea de que el universalismo pan-europeo se ha manifestado, al menos, en tres etapas: 1) la distinción civilización/barbarie 2) el particularismo esencialista y 3) el cientificismo universalista. A continuación se describen estas tres etapas someramente de acuerdo a lo desarrollado por Gallegos y del Valle (2013).

Generalizando, se parte de la distinción excluyente civilización/barbarie se funda a través de los filósofos de la Ilustración, quienes resaltan las diferencias entre un endogrupo y un exogrupo claramente distinguibles, atribuyendo en la mayoría de los casos características negativas a aquellos que no eran "modernos/desarrollados/ ilustrados". Toda esta categorización-diferenciación entre barbaros y civilizados se extiende desde el encubrimiento de América hasta mediados del siglo XIX, es decir, más de 400 años. 


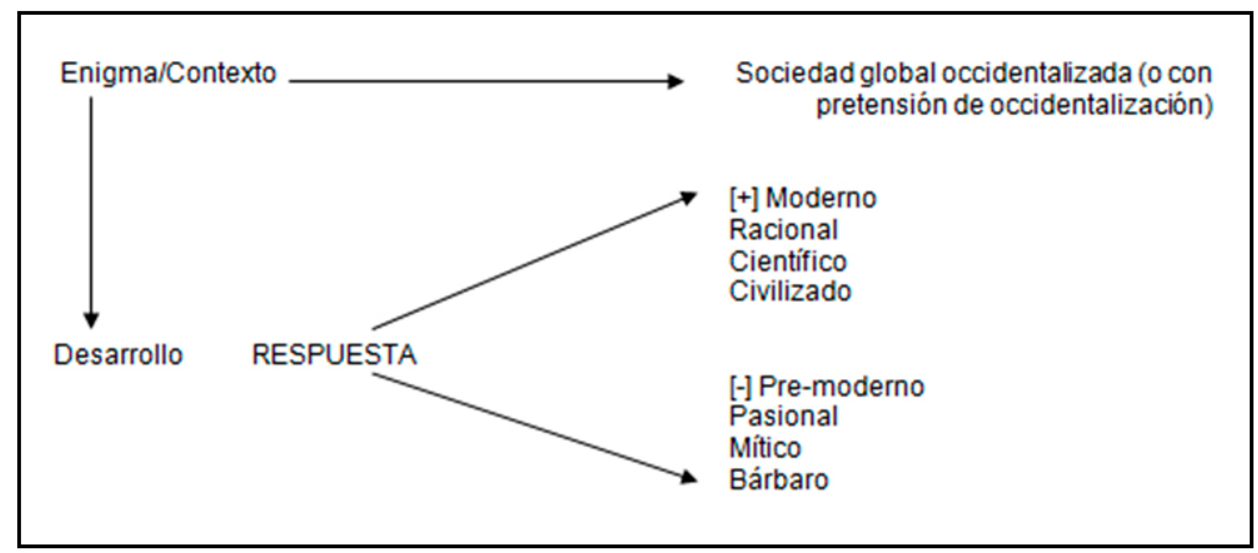

Figura 1. Imaginario nuclear de la sociedad occidental. Fuente: Elaboración propia.

Al mismo tiempo que se (re)creaba la distinción civilización/barbarie se sentaban las bases para un nuevo tipo de universalismo, escondido ahora, por paradojal que parezca, tras la máscara de las particularidades. Latinoamérica aparece así visualizada como un todo homogéneo a la usanza de lo que Said, denominó "orientalismo":

"Si tomamos como punto de partida aproximado el final del siglo XVIII, el orientalismo se puede describir y analizar como una institución colectiva que se relaciona con Oriente, relación que consiste en hacer declaraciones sobre él, adoptar posturas con respecto a él, descubrirlo, enseñarlo, colonizarlo y decidir sobre él; en resumen, el orientalismo es un estilo occidental que pretende dominar, reestructurar y tener autoridad sobre Oriente" (Said, 2002, p. 21).

Con el sólo cambiar la caracterización "orientalismo" por "latinoamericanismo", nos damos cuenta de que las mismas dinámicas avasalladoras descritas por Said, se han venido construyendo desde el siglo XV en las Américas ${ }^{5}$. Podríamos igualar esta idea con el concepto de "indigenismo" o más aún con el de "interculturalidad" toda vez que es usado como un sinónimo del primero a través del cual se procede a un reduccionismo analítico donde el otro aparece como "esencialmente" indígena, al tiempo que se toma su particularidad con un fin universal: que alcance la "modernidad/ desarrollo" o al menos pueda adaptarse a esta.

5. Ahora bien, el propio concepto de "Latinoamérica" adquiere un contenido colonial-moderno en cuanto construcción simbólico-imaginaria que es preciso rastrear y cuestionar a propósito de la invención europea de este concepto. Al respecto, Mignolo (2007) señala que otros conceptos ya habían acuñados por la población indígena antes de la llegada europea. Tres son en particular los conceptos señalados por Mignolo: Tawantinsuyu, referido a la región andina; Anáhuac al valle de México y Abya-Yala al territorio panameño actual. 
La última fase del pensamiento desarrollista se relaciona con un ideal objetivista que posiciona la tecno-ciencia como camino al desarrollo y al cumplimiento de los ideales ilustrados de la modernidad, lo que Wallerstein (2007) llama universalismo cientificista. Es así como podemos ver hoy, y aún enmarcados dentro de los ideales de progreso y desarrollo, un intento de validación del desarrollo capitalista a través de las conceptualizaciones "científicas" que intentan una vez, pero ahora con una verborrea "intelectual" acabar con las diferencias y subyugar las formas de expresión más propias de las Américas con el fin de dar paso al desarrollo.

Hipotéticamente, y como parte del diagnóstico acerca de las significaciones sociales nucleares de la sociedad occidental, del Estado-nación y de la relación mapuche/ no-mapuche, las fases diferenciadas que hemos descrito someramente (civilización/ barbarie; particularismo esencialista y cientificismo universal) son significaciones sociales periféricas que se articulan en torno a la institución imaginaria central de la modernidad/desarrollo. Considerando que todas estas significaciones sucesivas funcionan con muchas continuidades y reminiscencias de los periodos anteriores (un magma que da continuidad y recrea una lógica "ensídica").

El imaginario nuclear de desarrollo/modernidad hasta aquí descrito permea las esferas de las prácticas comunicativas (Del Valle, 2007), prácticas de enseñanza visualizadas a través de los programas de estudio (Del Valle, 2004), la acción política en el marco de los movimientos sociales étnicos (Gallegos, 2011), donde el liberalismodesarrollista actual se manifiesta incapaz de resolver las cuestiones de diferencia y reconocimiento de las minorías (Llera, 2008), e igualmente de garantizar el pluralismo y el pleno desarrollo de la libre expresión de los derechos individuales (Rodríguez, 2002). Todas estas esferas se vuelven significaciones sociales periféricas o instituciones segundas que fortalecen la significación social nuclear de desarrollo/modernidad.

En resumen, la distinción-construcción entre un nosotros y los otros, entre lo mapuche y lo no-mapuche, es posible de ser rastreada desde el siglo XVI con el nacimiento del sistema mundo capitalista que sitúa el comienzo de un proyecto mundial civilizatorio impulsado por el proyecto ilustrado-moderno, donde se configura una institución imaginaria de la sociedad (siguiendo a Castoriadis) que se basa en la idea de modernidad/desarrollo con todos los símbolos y significaciones inherentes. En todas sus variables los ideales de la modernidad y el desarrollo se presentan con claros elementos difusionistas que (re)producen la distinción entre sujetos poseedores de la verdad o "iluminados" y sujetos desplazados y vaciados de su alteridad con el fin de transformarlos en identidad, es decir, lo mismo que los otros; opera a decir de Sloterdijk (2006) un parque humano normativo caracterizado por un "humanismo [humanización] global pragmático y programático" (Sloterdijk, 2006, pp. 24-25) y que el filósofo alemán también remite como punto de partida a los procesos coloniales generados a partir del encubrimiento, particularmente luego de la primera vuelta al mundo (Sloterdijk, 2010). 
Remitir al imaginario de la modernidad-desarrollo para el estudio de la conformación de la identidad y la alteridad en situaciones de (des)encuentro étnico resulta imprescindible si consideramos que sus variantes y repercusiones discursivas se han dejado sentir por más de cinco siglos a lo largo y ancho del globo.

“(...) la reconstrucción del mundo moderno conlleva el desvelamiento de las tensiones o fricciones existentes entre dos dimensiones de la realidad social: por un lado, la dimensión totalizante del sistema social fundado en la sociedad mundial como monetarización y burocracia; por otro lado, la dimensión del mundo de la vida, en la cual se recupera la importancia de los procesos experimentados por los sujetos de forma interaccional con otros, de socialización e individuación" (Martínez \& Muñoz, 2009, p. 215).

En este sentido, nos gusté o no, el imaginario moderno-desarrollista que hemos caracterizado de manera sucinta, se constituye en un denominador común a la hora de visualizar una serie procesos y problemáticas sociales. Así, cabe para este imaginario la conceptualización de Castoriadis en cuanto a que constituye un imaginario dominante.

La ideología y el imaginario social del progreso y de la modernidad han sido, evidentemente, una ideología y un imaginario que, no obstante, se han difundido al conjunto de las sociedades latinoamericanas que finalmente aceptaron tales contenidos (...) Así, por ejemplo, la crítica del "progreso occidental" y de todos sus innumerables subentendidos queda sumergida en el desprestigio de un pensamiento perfectamente arcaico, irracional y nostálgico, que conspiraría contra intereses superiores, por cierto íntimamente ligados a ese modelo de progreso (Baeza, 2003, p. 116). 


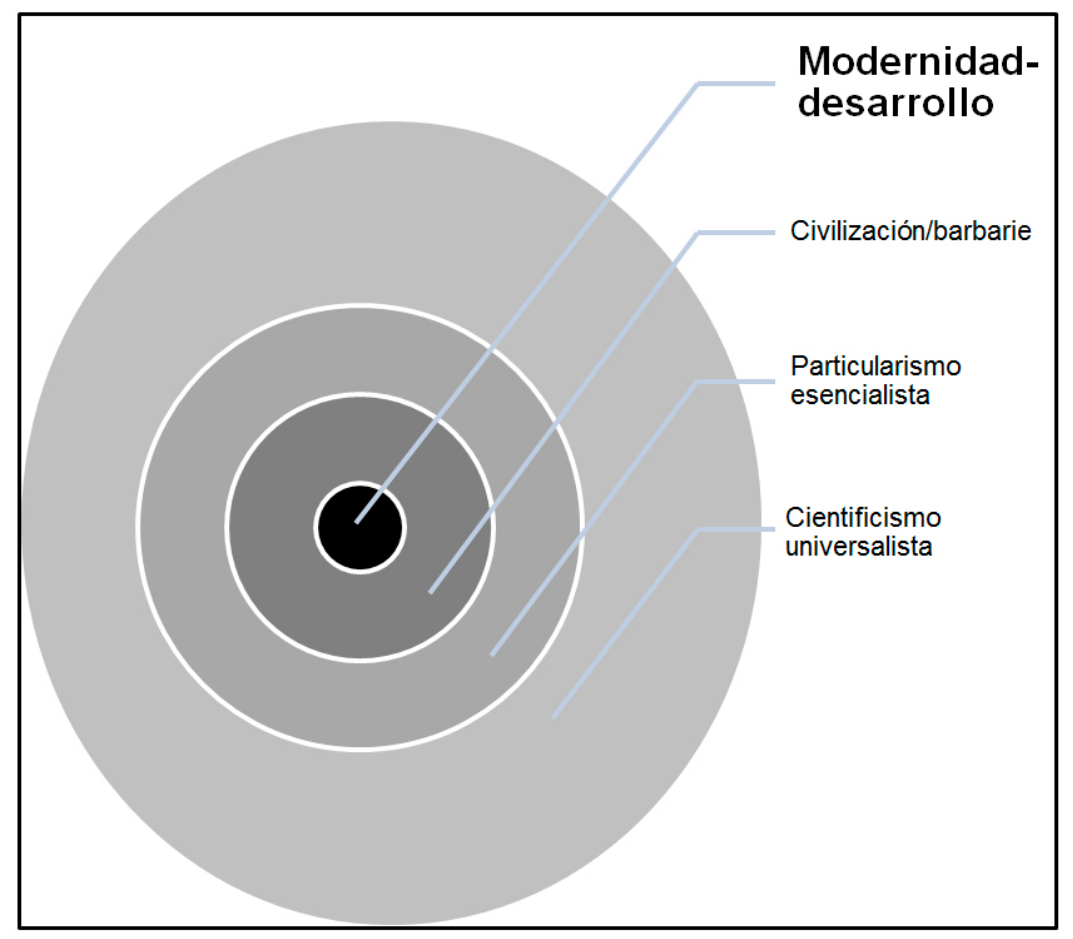

Figura 2. Imaginarios periféricos asociados a la modernidad/desarrollo. Fuente: Elaboración propia.

\subsection{El imaginario nuclear mapuche}

Para dar cuenta del imaginario nuclear del pueblo mapuche, remitiremos al mito de origen que se menciona en la bibliografía especializada como el más importante, estable y permanente de los mitos del pueblo mapuche; el mito de Treng-Treng y Kai-Kai ${ }^{6}$ (Carrasco, 1986, 1990, 1996; Fritz y Contreras, 1989). En síntesis el mito de TrengTreng y Kai-Kai, relata la lucha entre la serpiente Kai-Kai que hace subir las aguas y amenaza con la desaparición de los hombres, mientras que la serpiente Treng-Treng hace que un monte donde se han refugiado algunos humanos crezca y se eleve para salvarlos de las aguas. En algunas variantes, la lucha entre ambas serpientes llega a su fin mediando el sacrificio de un niño (Díaz, 2007).

El mito de Treng-Treng y Kai-Kai se trata de un mito de origen que no es exactamente una cosmogonía ya que el mundo y el hombre ya habían sido creados antes del suceso de Treng-Treng y Kai-Kai. Según Trivero (1999) la cosmogonía básica ma-

6. Algunas de las variaciones sintácticas "Tenten” y "Caicai”, "Xeg-xeg” y "Kai-Kai”, se agrega en otras denominaciones el sufijo "vilu" o "filu" que remite al hecho de que tanto Treng-Treng como Kai-Kai son serpientes o culebras (Díaz, 2007; Trivero, 1999). 
puche se relaciona con la lucha entre el pillán Antü y Peripillán, especies de espíritus antiguos y padres de Treng-Treng y Kai-Kai de manera respectiva. Sin embargo, Carrasco (1986) señala que es posible que las cosmogonías mapuches de las que se tiene noticia sean sólo fruto del contacto con la sociedad mayoritaria española y por lo tanto adaptaciones de la cosmogonía cristiana. Más allá de pretender dar cuenta de si las cosmogonías y los mitos sucesivos han sufrido o no afectaciones por parte de la cultura occidental, lo que interesa aquí es dar cuenta de la naturaleza dicotómica de lo que se reconoce hoy en día como parte del pensamiento mítico mapuche, y que es reivindicado por los propios mapuches.

Así, lo importante de retener aquí, es que detrás del mito de Treng-Treng y Kai-Kai es posible encontrar una lógica subyacente que sustenta, y es sustentada por una percepción cognitiva mítica, es decir un imaginario social. Algunos mitos han logrado subsistir a través del tiempo y se han constituido en parte de la tradición de grupos étnicos, estableciéndose como "núcleos permanentes de su identidad cultural" (Carrasco, 1990, p. 101).

"Lo que el mito intenta es preservar ciertos criterios intemporales, determinados valores transhistóricos, principios universales y permanentes, entretejidos con jirones culturales del espacio y época en que se generan los textos recreadores y reactualizadores de verdades milenarias e inmutables" (Carrasco, 1990, p. 103).

Así, Treng-Treng y Kai-Kai se constituye en un mito de origen porque está en el inicio de los mapuche como mito (re)fundador; se presenta como re-creación del mundo y regeneración del hombre con un sentido escatológico (Fritz \& Contreras, 1989). Este sentido escatológico tiene que ver con la renovación cíclica y la conservación del equilibrio cíclico que es una de las bases epistémicas de la cultura mapuche con importancia de las figuras de fuerza, simetría y dualidad (Carrasco, 1990; Grebes, Pacheco y Segura, 1972). Este principio dicotómico ha sido también señalado por autores mapuche contemporáneos como Huisca (1992) a propósito del concepto de ngen. Por su parte, Curivil (1994) señala las "oposiciones binarias" (p. 111) propias de la cultura mapuche que se actualizan en el caso del movimiento campo-ciudad llevado a cabo por muchos mapuche y que se traduce en una cultura de resistencia y creatividad frente a estos desplazamientos espaciales y sociales.

Es preciso re-construir las "lógicas subyacentes del mito y las estructuras profundas de significado que se le atribuyen en culturas particulares" (Carrasco, 1996, p. 8), ya que, y siempre a modo de diagnóstico, estás lógicas míticas y socio-imaginarias estarían impregnando las relaciones de conflicto entre Pueblo mapuche y Estadonación. 


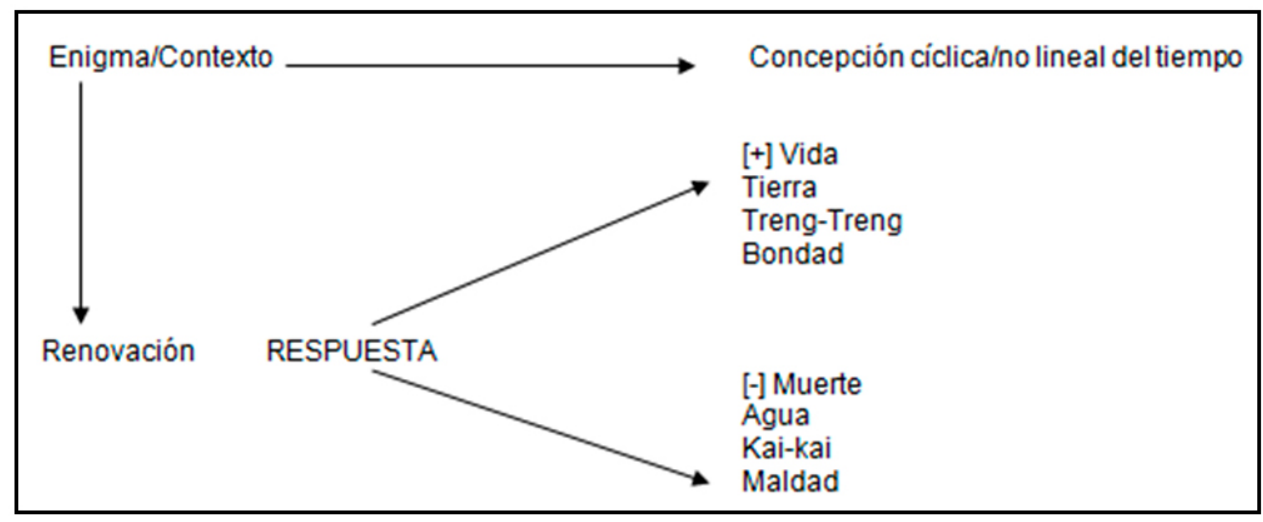

Figura 3. Imaginario nuclear mapuche.

Fuente: Elaboración propia.

En este sentido, y al hablar de "lógicas profundas de significado", es que no puede obviarse el hecho de que lo mítico está del todo asociado a lo simbólico, por lo cual sería más pertinente hablar de lo mítico-simbólico.

Así, conviene preguntarse hoy acerca de si el mito de Treng-Treng y Kai-Kai que hemos descrito como parte del imaginario nuclear mapuche se corresponde con símbolos que lo actualizan. U otra suerte de preguntas: ¿Treng-Treng y Kai-Kai es hoy mito, símbolo o ambas?

"Sin entrar a discutir el problema en detalle, lo que corresponde a otros especialistas, pensamos que mito y símbolo provienen de una fuente común: la que más atrás se ha llamado pensamiento mítico (o mentalidad, conciencia, imaginación, racionalidad, etc., míticas)" (Carrasco, 1996, p. 9).

En las lecturas ya citadas en este apartado, se deja entrever que diversos autores han tomado está postura de señalar que el mito de Treng-Treng y Kai-Kai se constituye en símbolos que se actualizan hoy en el marco del conflicto Estado-Nación/Pueblo Mapuche. Así, García (2010) señala que en el marco del arte mapuche actual, particularmente en la poesía y en la pintura, aparecen las figuras de Treng-Treng y Kai-Kai para representar el "conflicto mapuche" actual:

"Desde la lectura de trasgresiones, debido a las permanentes irrupciones e imposiciones de orden hegemónicas con que se instala occidente en el territorio mapuche inscribiendo ideologías y por lo tanto conductas opuestas a la norma ética ancestral, los actuales artistas mapuches adoptan como referente la lucha de Txen Txen y Kai Kai para desplegar un significado que va más allá del mito del diluvio, representando a través de ellas "las etapas del conflicto mapuche" (García, 2010, p. 53). 
Este carácter simbólico del mito y su fuerte componente identitario-imaginario podría relacionarse con las vinculaciones que se dan entre las nociones de tiempo, pensamiento filosófico y la propia lengua mapuche según lo expuesto por Loncon (2017; 2019). Al respecto, la autora señala la importancia del tiempo como parte de la filosofía indígena ligado al tiempo cíclico y al permanente retorno. En este sentido Loncon (2019) también apuntala complementariedad entre opuestos -a propósito de los binarismos antes referidos- y como esta forma en permanente tensión y circularidad interpela, tensiona o choca con la matematización del tiempo occidental orientada al progreso y a la linealidad con enfoque productivista.

De modo que lo que aquí se propone entender como imaginario nuclear de la cultura mapuche, el mito de Tren-Treng y Kai-Kai, vendría a ser ese sedimento estructurante (en palabras de Castoriadis) que permite la construcción/imaginación identitaria del Pueblo mapuche y que se actualiza en el marco del conflicto con el Estado-nación. Así mismo, y apuntando hacia la misma idea, Díaz (2007) señala:

"El mapuche de hoy, desde diversas puntos de vista, está reelaborando su identidad y reestructurando su lucha, su resistencia. El pensamiento mítico, está lejos de ser una forma primitiva de razonar, sino al contrario, en su carácter holístico, se revela tan capaz coma el pensamiento histórico para ayudar a un pueblo a re-encontrar su camino" (p. 52).

Concretamente, el citado Díaz hace referencia concreta, por ejemplo, la existencia actual de una organización de comunicaciones denominada "Xeg-xeg" y formada exclusivamente por mapuches con formación profesional e interés en la "re-etnificación", ya que tienen como objetivo la recuperación de la cultura mapuche en el marco de un proceso de a-culturación que amenaza a la etnia... "El término Treng- Treng está siendo releído y usado en nuevos contextos que proponen una recuperación de la cultura" (Díaz, 2007, p. 48).

Así, es del todo pertinente preguntarnos acerca de la actualización que se hace de este mito que consideramos como el imaginario nuclear de la cultura mapuche actual. No es coincidencia entonces que en la relación intertextual del mito se aprecie la concordancia de Tren-Tren/Tierra/valor positivo y así mismo Kai-Kai/Agua/valor negativo (Carrasco, 1996). Este hecho se relaciona con otro; la tierra (mapu) es un elemento clave del Pueblo mapuche, mucho más que sustrato cultivable es la base de la cultura. Revelador es en este aspecto que mapuche es un concepto en mapuzungun -idioma mapuche- que podría traducirse como gente de la tierra.

"Esto será relevante en la pesquisa de las nuevas interpretaciones o variantes del mito original en nuevos contextos de violencia o conflicto que amenazan la comunidad. (...) Siendo el mito esencialmente un relato conservado y reinterpretado por la comunidad a la que pertenece; relato oral que 
sobrevive en la medida que la comunidad encuentra en él claves vigentes para interpretar la realidad en la que busca realizar su proyecto de vida, tenemos que preguntarnos cuáles son esas claves de interpretación que hacen que el mito esté vigente" (Díaz, 2007, pp. 50-51).

La pregunta acerca de la vigencia de lo mítico-simbólico descrito anteriormente tiene como finalidad poder dar cuenta de la significación imaginaria que se encuentra en la base de la lucha reivindicativa mapuche y por extensión en la relación con el Estado-Nación. No sería prudente obviar este elemento mítico-simbólico como potencialmente tributario de los imaginarios sociales actuales sobre el conflicto.

"Los imaginarios sociales, en tanto que gramáticas surgidas de una significancia práctica socialmente compartida, en tanto que esquemas instituyentes en distintos ámbitos, en situación de dominantes o de dominados, no escapan a los diferentes condicionamientos espacio-temporales (y también de contingencia) en donde surgen. Dotados de historicidad, al igual que toda "obra humana", los imaginarios sociales no pueden sino reconocer, en definitiva, sus propios contextos de elaboración, y de los cuales son parcial o totalmente tributarios" (Baeza, 2003, p. 36).

\section{Consideraciones finales: ¿antagonismo radical basado en imaginarios nucleares irreconciliables?}

El diagnóstico realizado en las páginas precedentes en torno a los imaginarios nucleares que articulan la significación del mundo del Estado-nación de Chile y el Pueblo mapuche dan cuenta de diferencias sustantivas en lo que es finalmente la visión de sociedad o país a construir; debido a que los imaginarios sociales intervienen ineludiblemente en la conformación de mundo incluida aquí las estructuras sociales de cualquier índole sean estas de raza, nación, clase, género, etc. La unificación social que opera en un momento socio-histórico específico, y relacionado por ejemplo, con la conformación imaginaria de un nosotros/otros o de una identidad diferenciada de una alteridad, es posible precisamente por la unidad de los imaginarios que representan un conjunto coherente de universos simbólico-significantes.

En complemento se desprende también que los imaginarios sociales no pueden existir de manera separada, sino que deben estar en una constante correlación, en disputas, ajustes y transformaciones que se adecúan al momento socio-histórico por el que atraviesa, ya que la sociedad sólo puede existir en este soporte imaginario de los cuales, querámoslo o no, todos sus miembros participan (Riffo, 2016, p. 65). 
En este sentido, resulta relevante en el marco del contexto socio-histórico actual caracterizado por un movimiento social mapuche activo y que interpela al Estado en torno a las injusticias históricas, entender las dinámicas socio-políticas que se dan en este marco a la luz de los imaginarios sociales nucleares y periféricos a los que cada parte del conflicto echa mano para (re)construir sus discursos y prácticas. Al mismo tiempo, apunta a un reconocimiento de los "mundos y epistemologías en resistencia" (Quidel, 2020), donde la temporalidad como parte de un kimün y la interacción entre el nosotros y los otros aparece como parte del horizonte comprensivo de entendimiento y respeto mutuo, intentando superar las narrativas de negación que, por ejemplo, desde la historia escolar y la linealidad occidental han avasallado la identidad indígena (Turra, Catriquir y Valdés, 2017).

Las diferencias explicitadas aquí en los imaginarios nucleares dan cuenta de que el Pueblo mapuche orienta sus prácticas e identidad en torno a una concepción cíclica del tiempo que tiende a la renovación, donde se busca una actualización o revitalización de la cultura y lo propio. Por el contrario, el Estado-nación chileno orienta sus prácticas discursivas con miras al desarrollo constante y la modernización consecuente que conlleva el abandono de lo no-moderno y no-desarrollado?

En este sentido, se visualizan imaginarios nucleares basados en dicotomías irreconciliables, tanto por parte del Pueblo mapuche como del Estado-nación, estas dicotomías irreconciliables generan un sistema de significados fuertemente orientados a la lucha y el conflicto; el Estado-nación lucha por su parte con la idea de lo pre-moderno donde se actualiza la dicotomía civilización/barbarie, mientras que el Pueblo mapuche lucha por la renovación cíclica interpelando a una sociedad mayoritaria que lo acorrala, tal como las aguas (Kai-Kai) amenazaban la existencia del Pueblo mapuche en el mito revisado y que encuentra su resolución positiva en la tierra (Tren-Tren) que aparece como el recurso de la vida y la renovación. Así, sería posible hablar de la idea de un antagonismo radical que no se sustenta tan solo en la lucha política o las diferencias de proyectos políticos de un grupo y otro, sino que tendría un sustrato mucho más profundo y arraigado en los imaginarios sociales nucleares sedimentados desde más de 500 años. Al respecto, las concepciones diferenciadas de temporalidad (cíclica en el caso indígena y lineal en el caso occidental) dificultan y amplifican el antagonismo en torno a la consecución de fines distintos.

\footnotetext{
7. Sin embargo, no se desconoce que ha sido el Pueblo Mapuche quienes como sujetos excluídos han dado cuenta de procesos de "bilingüismo" (tanto lingüístico como cultural) y han sido capaces de habitar en una temporalidad diversa e híbrida. En este sentido, quizás las ideas de "heterogeneidad multitemporal" (entiéndase "heterogeneidad temporal" o "multitemporalidad") desarrolladas por García (1989), sean todavía útiles para entender el proceso de encuentro que viene desde la sociedad occidental hacia el respeto de otras formas de cosmovisión y temporalidades no lineales como las aquí presentadas.
} 
Así, y en su afán por llevar a cabo el proyecto modernizador el Estado invisibiliza en muchas ocasiones a la alteridad mapuche y los trata como si fueran identidad, es decir, lo mismo que el Estado, no importando así y avasallando las diferencias, que tal como lo menciona Sánchez (1999) se actualiza en violencia y represión ${ }^{8}$ :

"Cuando una forma social, como la moderna actualmente, hace de "su" universo simbólico de carácter sistémico-funcional "el" universo simbólico del todo social elimina la posibilidad de otras formas de apalabrar el mundo, se produce un proceso de empobrecimiento cultural y de desimbolización donde el antagonismo y politeísmo soterrado se reducen unidimensionalmente a favor de uno de los polos, todo lo cual permite desembocar (en el caso moderno) en formas sociales hiperracionales portadoras de una gran carga de violencia y represión hacia la diferencia" (Sánchez Capdequí, 1999, p. 94).

Esta situación de avasallamiento, violencia y represión apuntaría también la idea del antagonismo radical; dinámica compleja que debe ser observada con atención por los teóricos y estudiosos sociales con miras a, entre otras cosas, dar cuenta de las relaciones de inter-culturalidad que se dan en nuestras sociedades, considerando los aspectos aquí mencionados en torno a los imaginarios nucleares que constituyen identidades y/o alteridades. En este sentido, cabría preguntarse dónde pueden o podrían encontrarse los elementos para una verdadera inter-cultura concepto en extremo manoseado por las políticas públicas y los simulacros de democracia. Sobre esto, Nahuelpán (2015) señala a propósito de los desafíos para un diálogo epistémico intercultural la necesidad del descentramiento epistémico y la consideración de marcos de conocimiento en interacción y complementaridad entre sociedades distintas.

Respecto de la especificidad del imaginario nuclear aquí propuesto y descrito para la comprensión del Pueblo mapuche y sus reivindicaciones actuales, queda trabajo por hacer en relación a la vinculación de sus prácticas con el imaginario de la renovación cíclica antes descrito. Algunas preguntas que podrían abordarse pueden ser, sin ánimo de exhaustividad, las siguientes: ¿cuáles son las prácticas donde se vislumbra el imaginario nuclear? ¿cuáles y cómo son los imaginarios periféricos que se configuran en torno al imaginario nuclear de la renovación cíclica? ¿cómo se actualiza esta renovación cíclica y que elementos del mito de renovación se traspasan a sus prácticas discursivas? Intentado dar respuesta a estas preguntas se podría considerar si acaso el mundo imaginario guía la cotidianidad y las relaciones en el mundo socio-histórico en sus prácticas cotidianas.

8. Ver también la distinción que realiza De Sousa Santos $(2004,2009)$ en torno al tiempo estatallineal y el tiempo cíclico local-global. 


\section{Referencias}

Alvarez-Gayou, Juan (2003). Cómo hacer investigación cualitativa. Ed. Paidós. México.

Anderson, Benedict (1993). Comunidades imaginadas. Fondo de Cultura Económica. México, D.F.

Baczko, Bronislaw (2005). Los imaginarios sociales: memorias y esperanzas colectivas. Ed. Nueva Visión. Buenos Aires.

Baeza, Manuel (2003). Imaginarios sociales: apuntes para la discusión teórica y metodológica. Universidad de Concepción eds. Concepción.

Baeza, Manuel (2008). Mundo real, mundo imaginario social. RIL editores. Santiago.

Bengoa, José (2002). Historia de un conflicto: el estado y los mapuche en el siglo $x x .2^{\mathrm{a}}$ edición. Ed. Planeta. Santiago.

Carrasco, Hugo (1986). El repertorio de funciones del relato mítico mapuche. Revista de Lenguas y Literatura Mapuche, 2, 21-34.

Carrasco, Hugo (1990). La matriz de los mitos de transformación. Revista de Lenguas y Literatura Mapuche, 4, 122-132.

Carrasco, Hugo (1996). Reviviendo historias antiguas. Instituto de Estudios Indígenas / Universidad de La Frontera, editores. Temuco.

Castoriadis, Cornelius (2004). Sujeto y verdad en el mundo histórico - social: Seminarios 1986 - 1987. La creación humana I. F.C.E. México D.F.

Castoriadis, Cornelius (2005). Figuras de lo pensable. Ed. F.C.E. Buenos Aires.

Castoriadis, Cornelius (2007). La institución imaginaria de la sociedad. Tusquets editores. Buenos Aires.

Castro-Gómez, Santiago (2005). La hybris del punto cero: ciencia, raza e ilustración en la Nueva Granada (1750-1816). Bogotá: Pontificia Universidad Javeriana.

Curivil, Ramón (1994). Análisis del discurso de una comunidad ritual. Lengua y Literatura Mapuche, 6, 103-113.

Dávila, Gladys (2006). El razonamiendo inductivo y deductivo dentro del proceso investigativo en ciencias experimentales y sociales. Revista Laurus 12, $\mathrm{n}^{\circ}$ Ext, 180205.

Del Valle, Carlos (2004). Los indígenas de Chile en las Relaciones de Sucesos españolas: Representación y memoria desde la interculturalidad. Revista Zer de Estudios de Comunicación, 16, 121-136.

Del Valle, Carlos (2007). Comunicación Participativa: Aproximaciones desde América Latina. Revista Redes, 4, 113-130. 
De Sousa Santos, Boaventura (2004). Reinventar la democracia: reinventar el Estado. Quito: Editorial.

De Sousa Santos, Boaventura (2009). Una epistemología del sur: la reinvención del conocimiento y la emancipación social. Ciudad de México: Siglo XXI

Díaz, José (2007). El mito de "treng-treng kai-kai" del pueblo mapuche. Revista CUHSO, 14 (1): 43-53.

Dube, Saurabh (2009). Modernidad. En: Szurmuk, M. \& Mckee, R. (coords.) Diccionario de Estudios Culturales Latinoamericanos (pp. 175-180). Siglo XXI editores. México.

Fritz, Rubén \& Marcos Contreras (1989). El origen del mundo y del hombre en relatos orales de la cultura mapuche. Revista de Lengua y Literatura Mapuche, 3, 103-114.

Gallegos, Eduardo (2011). Identidades excluidas y formas de acción política. El caso de las huelgas de hambre mapuche: entre la desobediencia civil y la violencia política. Revista Polis, 10 (28): 161-173.

Gallegos, Eduardo \& Carlos del Valle (2013). La modernidad/desarrollo y el avasallamiento de la alteridad en la tradición latinoamericana. Elementos para una genealogía crítica del pensamiento colonial y del modelo desarrollista. Revista Magriberia, 8, 219-231.

García, Mabel (2010). La construcción del relato mítico ancestral en el arte y la poesía mapuche actual. Papeles de trabajo, CEIEAS, 20.

García, Néstor (1989). Culturas híbridas. México: Grijalbo.

Grebes, María, Sergio Pacheco y José Segura (1972). Cosmovisión mapuche. Cuadernos de la realidad nacional, 14, 46-73.

Huisca, Rosendo (1992). ¿Vivencia o convivencia de dos mundos? Actas de Lengua y Literatura Mapuche, 5, 145-147.

Kant, Inmanuel (2004). Filosofía de la historia. Ed. Terramar, La Plata.

Llera, Mar (2008). ¿Cómo se enfrenta el liberalismo al desafío de la multiculturalidad? En: del Valle, C. et. al. (Eds.) Contrapuntos y entrelineas sobre cultura, comunicación y discurso (pp. 471-485). Ediciones Universidad de La Frontera, Temuco.

Loncon, Elisa (2019). Una aproximación al tiempo, el pensamiento filosófico y la lengua mapuche. Árboles y Rizomas, I (2), 67-81.

Loncon, Elisa (2017). El Mapuzugun desde el pensamiento mapuche: Pasado, presente y futuro. Americanía. Revista de Estudios Latinoamericanos. Nueva Época, Número Especial, 204-219.

Martínez, Jorge \& Diego Muñoz (2009). Aproximación teórico-metodológica al imaginario social y las representaciones colectivas: apuntes para una comprensión sociológica de la imagen. Universitas humanística, 67, 207-221. 
Mayorga, Javier, Carlos del Valle y Rodrigo Brown (2013). El imaginario social de la acción colectiva de protesta y la crisis Argentina de 2001, en el discurso de la prensa en Chile. Revista Polis, 34.

Millalén, José (2012). Taiñ mapuchegen. Nación y nacionalismo Mapuche: construcción y desafío del presente. En: AA. VV. Ta iñ fijke xipa rakizuameluwün. Historia, colonialismo y resistencia desde el país Mapuche. (pp. 241-258). Temuco: Ediciones Comunidad de Historia Mapuche.

Mignolo, Walter (2007). La idea de América Latina. Barcelona: Gedisa.

Nahuelpán, Héctor (2007). El sueño de la identidad latinoamericana o la búsqueda de lo propio en lo ajeno. Atenea, 495, 157-164.

Nuelpán, Héctor (2015). Los desafíos de un diálogo epistémico intercultural: pueblo mapuche, conocimientos y universidad. En: VV.AA. Prácticas otras de conocimiento(s) (pp.159-180). Buenos Aires: Clacso.

O’Gorman, Edmundo (1995). La invención de América. 4ta. Reimpresión. México: Fondo de Cultura Económica.

Pinto, Jorge (2003). De la inclusión a la exclusión: la formación del estado, la nación y el pueblo mapuche. $2^{\text {a }}$ edición. Eds. Dibam. Santiago.

Pinto, Jorge (2008). Proyectos de la elite chilena del siglo XIX (I). Revista Alpha, 26, 167-189.

Quidel, José (2016). El quiebre ontológico a partir del contacto mapuche hispano. Chungará, Revista de Antropología Chilena, 48(4): 713-719.

Quidel, José (2020). Mundos y epistemologías en resistencias: el caso del Pueblo Mapuche. CUHSO, 221-232.

Quijano, Aníbal (200o). Colonialidad del poder, eurocentrismo y América Latina. En E. Lander (comp.) La colonialidad del saber: eurocentrismo y ciencias sociales. Perspectivas latinoamericanas. (pp. 201-246). Buenos Aires: Clacso.

Quiroga, Samuel \& Lorena Villegas (2016). Wallmapu. En I. Salgado (comp.) Travesías por la Araucanía (pp. 281-194). Temuco: Ediciones Universidad Católica de Temuco.

Riffo, Ignacio (2016). Una reflexión para la comprensión de los imaginarios sociales. Revista Comuni@cción, 7(1):63-76.

Rodríguez, Roberto (2002). Liberalismo, pluralismo y política. Notas para una política del pluralismo. Revista Laguna 10. pp 167- 189.

Saavedra, Alejandro (2002). Los mapuche en la sociedad chilena actual. LOM editores. Santiago.

Said, Edward (2002). Orientalismo. Ed. Debate. Madrid. 
Salazar, Juan (2002). Activismo indígena en América Latina: estrategias para una construcción cultural de las tecnologías de información y comunicación. Journal of Iberian and Latin American Research, 8(2), 61-80.

Sánchez, Celso (1999). Imaginación y sociedad: una hermenéutica creativa de la cultura. Editorial Tecnos. Madrid.

Sloterdijk, Peter (2006). Normas para el parque humano. $4^{\text {a }}$ edición. Ediciones Ciruela. Madrid.

Sloterdijk, Peter (2010). En el mundo interior del capital. $2^{\mathrm{a}}$ edición. Ediciones Ciruela. Madrid.

Tricot, Tito (2009). El nuevo movimiento mapuche:hacia la (re)construcción del mundoy país mapuche. Revista Polis, 8 (24): 175-196.

Trivero, Alberto (1999). Trentrenfilú. Recuperado de http://www.prodiversitas.bioetica.org/triv1.html.

Turra, Omar, Desiderio Catriquir \& Mario Valdés (2017) . La identidad negada: historia y subalternización cultural desde testimonios escolares mapuche. Cadernos de pesquisa, 47(163): 342-356.

VV.AA. (2012) Ta iñ fijke xipa rakizuameluwün. Historia, colonialismo y resistencia desde el país Mapuche. Temuco: Ediciones Comunidad de Historia Mapuche.

Wallerstein, Inmanuel (2006). Análisis de sistemas mundos. Una introducción. México: siglo XXI.

Wallerstein, Inmanuel (2007). Universalismo Europeo: el discurso del poder. Siglo XXI, México D.F.

\section{Sobre el autor}

Eduardo Gallegos Krause es Académico Departamento de Lenguas, Literatura y Comunicación; Universidad de La Frontera Doctorando en Comunicación; Universidad de La Frontera-Universidad Austral de Chile. Becario Agencia Nacional de Investigación y Desarrollo, ANID. Correo Electrónico: eduardo.gallegos@ufrontera. cl. (i) https://orcid.org/0000-0002-8560-7367 


\title{
CUHSO
}

Fundada en 1984, la revista CUHSO es una de las publicaciones periódicas más antiguas en ciencias sociales y humanidades del sur de Chile. Con una periodicidad semestral, recibe todo el año trabajos inéditos de las distintas disciplinas de las ciencias sociales y las humanidades especializadas en el estudio y comprensión de la diversidad sociocultural, especialmente de las sociedades latinoamericanas y sus tensiones producto de la herencia colonial, la modernidad y la globalización. En este sentido, la revista valora tanto el rigor como la pluralidad teórica, epistemológica y metodológica de los trabajos.

\author{
EDITOR \\ Matthias Gloël \\ COORDINADORA EDITORIAL \\ Claudia Campos Letelier \\ CORRECTOR DE ESTILO Y DISEÑAdOR \\ Ediciones Silsag \\ TRADUCTOR, CORRECTOR LENGUA INGLESA \\ Aurora Sambolin Santiago \\ SITIO WEB \\ cuhso.uct.cl \\ E-MAIL \\ cuhso@uct.cl \\ LICENCIA DE ESTE ARTÍCULO \\ Creative Commons Atribución Compartir Igual 4.0 Internacional
}

